Support statement: This analysis was funded by AstraZeneca.

Conflict of interest: Disclosures can be found alongside the online version of this article at erj.ersjournals.com

Acknowledgements: Medical writing assistance was provided by Shaun Foley and Clair Clowes of inScience Communications, Springer Healthcare (Chester, UK) and funded by AstraZeneca.

\title{
References
}

1 Global Initiative for Chronic Obstructive Lung Disease. Global strategy for the diagnosis, management, and prevention of chronic obstructive pulmonary disease. www.goldcopd.org/uploads/users/files/GOLD_Report_2011_Feb21.pdf Date last accessed: January 14, 2014. Date last updated: February 21, 2011.

2 Han MK, Muellerova H, Curran-Everett D, et al. GOLD 2011 disease severity classification in COPDGene: a prospective cohort study. Lancet Respir Med 2013; 1: 43-50.

3 Agusti A, Edwards LD, Celli B, et al. Characteristics, stability and outcomes of the 2011 GOLD COPD groups in the ECLIPSE cohort. Eur Respir J 2013; 42: 636-646.

4 Lange P, Marott JL, Vestbo J, et al. Prediction of the clinical course of chronic obstructive pulmonary disease, using the new GOLD classification: a study of the general population. Am J Respir Crit Care Mede 2012; 186: 975-981.

5 Tashkin DP, Rennard SI, Martin P, et al. Efficacy and safety of budesonide and formoterol in one pressurized metered-dose inhaler in patients with moderate to very severe chronic obstructive pulmonary disease: results of a 6-month randomized clinical trial. Drugs 2008; 68: 1975-2000.

6 Rennard SI, Tashkin DP, McElhattan J, et al. Efficacy and tolerability of budesonide/formoterol in one hydrofluoroalkane pressurized metered-dose inhaler in patients with chronic obstructive pulmonary disease: results from a 1-year randomized controlled clinical trial. Drugs 2009; 69: 549-565.

7 Sharafkhaneh A, Southard JG, Goldman M, et al. Effect of budesonide/formoterol pMDI on COPD exacerbations: a double-blind, randomized study. Respir Med 2012; 106: 257-268.

8 Vogelmeier C, Vestbo J. COPD assessment: I, II, III, IV and/or A, B, C, D. Eur Respir J 2014; 43: 949-950.

\section{Occupational exposures and fluorescent oxidation products in 723 adults of the EGEA study}

\section{To the Editor:}

Occupational asthma can be induced by a variety of agents, including high and low molecular weight sensitisers, and respiratory irritants [1]. The role of exposure to cleaning products and disinfectants in work-related asthma is increasingly recognised, although the specific substances that increase asthma risk are not well identified [2]. Some of the numerous agents contained in these products are chemical sensitisers, but most are hypothesised to act as respiratory irritants [2]. While high molecular weight sensitisers are known to cause occupational asthma through a typical allergic response, the pathophysiological mechanisms involved in occupational asthma induced by low molecular weight (LMW) chemicals, and in irritant-induced asthma, remain poorly understood $[1,3,4]$.

Oxidative stress is one of the potential mechanisms causing epithelial injury, which may be especially relevant in irritant-induced asthma [1,4]. In this context, we sought to investigate the associations between occupational exposure to potentially asthmogenic chemicals and irritants, and the level of fluorescent oxidation products, a global marker of damage due to oxidative stress [5], in adults from the Epidemiological study on the Genetics and Environment of Asthma (EGEA).

The French EGEA combines a case-control and family-based study [6]. The baseline study (EGEA1; 1991-1995, n=2047) included cases with asthma, their first degree relatives, and population-based controls. The study protocol was approved by the relevant institutional review board committees (Cochin Port-Royal Hospital and Necker-Enfants Malades Hospital, Paris, France) and all participants gave written informed consent. The current analysis used data from the follow-up study (EGEA2; 2003-2007) and included only adults who had never had asthma $(n=888)$, in order to distinguish occupational exposures from the oxidative stress generated by the disease. 723 participants (328 men and 395 women) had fluorescent 
oxidation products measurements available and complete data for smoking habits, an environmental exposure related to oxidative stress.

Levels of fluorescent oxidation products were measured in plasma as described previously [5]. Briefly, plasma was extracted with 3:1 by volume ethanol/ether and was measured using a spectrofluorometer (360nm excitation wavelength, 430nm emission wavelength). The fluorescence was determined as relative fluorescent intensity units per millilitre of plasma $\left(\mathrm{RFU} \cdot \mathrm{mL}^{-1}\right)$.

Occupational history was recorded by questionnaire, and an asthma-specific job-exposure matrix (JEM) was used to evaluate exposure to agents potentially at risk for asthma or respiratory health [7]. Hospital workers (including healthcare workers or cleaners in hospitals) were further asked to complete a job-specific questionnaire regarding exposure to cleaning/disinfecting tasks and products. An expert assessment was also conducted to evaluate exposure to 18 specific products in hospital workers [8]. We chose to study the following occupational exposures, in the current or last job held, in relation to levels of fluorescent oxidation products: 1) exposure to cleaning/disinfecting products evaluated both by the JEM (a highly specific assessment in which only jobs with high probability of exposure to industrial cleaning products were classified as exposed), and by the expert assessment with a focus on cleaning/disinfecting products which are more likely to be respiratory irritants; and 2) exposure to LMW agents evaluated by the JEM.

Associations between occupational exposures and levels of fluorescent oxidation products were evaluated separately in men and women. We used linear regression of log-transformed levels of fluorescent oxidation products, adjusted for age and smoking habits. The coefficients obtained from the log-transformed fluorescent oxidation products models were back-transformed to obtain geometric mean (GM) ratios.

The GM (first quartile-third quartile) of fluorescent oxidation products level in all adults was 94.4 (81.9-108.1) RFU.mL ${ }^{-1}$. As expected [5], levels of fluorescent oxidation products increased with age $(\mathrm{p}<0.0001)$, were higher in women (age-adjusted GM (95\% CI) $\left.95.7(93.7-97.7) \mathrm{RFU} \cdot \mathrm{mL}^{-1}\right)$ than in men (92.9 (90.8-95.0) RFU.mL $\left.{ }^{-1} ; \mathrm{p}=0.06\right)$, and increased with current smoking. Among women, levels of fluorescent oxidation products were increased in current smokers (age-adjusted GM (95\%CI): 100.2 (95.5-105.2) RFU.mL $\left.{ }^{-1} ; \mathrm{p}=0.004\right)$ and ex-smokers (99.6 (95.6-103.7) RFU.mL $\left.{ }^{-1} ; \mathrm{p}=0.002\right)$ compared with nonsmokers (92.2 (89.7-94.8) RFU. $\left.\mathrm{mL}^{-1}\right)$. Among men, levels of fluorescent oxidation products were increased in current smokers (98.8 $\left.(94.0-103.7) \mathrm{RFU} \cdot \mathrm{mL}^{-1} ; \mathrm{p}=0.005\right)$, but were not significantly higher in ex-smokers (92.4 (88.7-96.3) RFU·mL ${ }^{-1}$; $\left.\mathrm{p}=0.51\right)$ compared with nonsmokers (90.7 (87.6-93.4) RFU.mL ${ }^{-1}$ ). Occupational exposure to irritant cleaning products and to LMW agents, especially highly reactive chemicals, were significantly associated with higher levels of fluorescent oxidation products in men (table 1). In women, an association was suggested $(\mathrm{p}=0.08)$ between occupational exposure to irritant cleaning products and levels of fluorescent oxidation products.

To our knowledge, this study is the first to show an association between occupational exposures to potentially asthmogenic chemicals and irritants, and levels of fluorescent oxidation products. Several studies have linked irritant exposures, such as cigarette smoke, to levels of fluorescent oxidation products $[5,9,10]$. By contrast, a study of 236 male workers in the truck industry did not find evidence for any association between occupational exposure to particulate matter and levels of fluorescent oxidation products, but the authors acknowledged limitations in the study power and occupational exposure assessment method [11]. In a study investigating asthma among 92 Spanish cleaning workers, no differences in levels of exhaled breath condensate 8-isoprostanes, a specific marker of lipid peroxidation, were observed according to case/control status or to self-reported occupational exposures to cleaning products [12]. However, levels of fluorescent oxidation products, as a nonspecific but global systemic measurement, has been suggested to be a better marker of oxidation as it measures products resulting from oxidation of lipids, proteins, amino acids, and DNA $[5,10]$.

This study included a relatively large sample of participants compared with the existing literature, although numbers were low for some exposure categories. One of the strengths of this study is the good characterisation of occupational exposures using expert assessment and an asthma-specific JEM, two complementary methods which do not rely on the workers' own report [13]. However, detailed assessment of exposure to the multiple chemicals contained in cleaning and disinfecting products is challenging, and the sample size did not allow us to study associations between levels of fluorescent oxidation products and specific agents, or a potential dose-response effect according to duration or timing of exposure.

For both exposure to irritant cleaning products and LMW chemicals, the associations were stronger and reached statistical significance in men ( $\mathrm{p}$-value for interaction ranging from 0.03 to 0.28 ). Results were similar after adjustment for body mass index (data not shown). Among exposed subjects, the main gender difference in occupations was that women were more often employed as personal care workers than men. We previously found, in EGEA2, that cleaning exposures among female healthcare workers were associated 
TABLE 1 Age- and smoking-adjusted associations between current occupational exposure and levels of fluorescent oxidation products in men and women

\begin{tabular}{|c|c|c|c|c|c|c|c|}
\hline Occupational exposure & \multicolumn{3}{|c|}{ Men } & \multicolumn{3}{|c|}{ Women } & $\begin{array}{l}\mathrm{p} \text {-value for } \\
\text { interaction }\end{array}$ \\
\hline Non exposed ${ }^{\#}$ (reference) & 180 & 1 & & 289 & 1 & & \\
\hline \multicolumn{8}{|l|}{ Cleaning products } \\
\hline 1) Industrial cleaning products (JEM) & 1 & & & 11 & $1.06(0.93-1.21)$ & 0.36 & \\
\hline $\begin{array}{l}\text { 2) Irritant cleaning products } \\
\text { (expert assessment) }\end{array}$ & 10 & $1.24(1.07-1.43)$ & 0.004 & 51 & $1.06(0.99-1.13)$ & 0.08 & 0.05 \\
\hline 1) or 2) & 11 & $1.24(1.08-1.42)$ & 0.002 & 52 & $1.05(0.99-1.12)$ & 0.12 & 0.03 \\
\hline \multicolumn{8}{|l|}{ LMW agents ( JEM) } \\
\hline Any LWM agent ${ }^{+}$ & 26 & $1.10(1.02-1.18)$ & 0.01 & 27 & $1.01(0.92-1.09)$ & 0.89 & 0.14 \\
\hline Highly reactive chemicals & 13 & $1.12(1.01-1.23)$ & 0.03 & 24 & $1.02(0.93-1.11)$ & 0.66 & 0.28 \\
\hline Metals & 11 & $1.05(0.95-1.17)$ & 0.34 & 1 & & & \\
\hline \multicolumn{8}{|c|}{$\begin{array}{l}\text { Jobs classified as exposed to irritant cleaning products lassessed among hospital workers only) included various healthcare-related occupations } \\
\text { (e.g. nursing professionals, personal care workers (mainly women), medical doctors, physiotherapists and life science technicians). Jobs } \\
\text { classified as exposed to highly reactive chemicals included chemists, biologists or pharmacologists, and jobs such as varnishers/painters, } \\
\text { embalmers or hairdressers. GM: geometric mean; JEM: job-exposure matrix; LMW: low molecular weight. " } \text { : nonexposed to any agent potentially } \\
\text { a risk for asthma or respiratory health (asthma-specific JEM); " }{ }^{\emptyset} \text { : including bleach, ammonia, decalcifiers, solvents, formaldehyde, glutaraldehyde, } \\
\text { alcohol, quaternary ammonium compounds, chloramine T, ethylene oxide, and disinfection or bio-cleaning tasks; }{ }^{+} \text {: including industrial cleaning } \\
\text { products, highly reactive chemicals, metals and diisocyanates. }\end{array}$} \\
\hline
\end{tabular}

with current asthma, with a potential role for both irritants and sensitisers [13]. A potential association between occupational exposures and oxidative stress may be more difficult to detect in these women experiencing exposure to multiple cleaning and disinfecting products, especially when further considering domestic exposures $[14,15]$. Gender differences may also be explained by the different ability to maintain redox status between men and women [16]. Larger studies are needed to further investigate the role of exposure to specific chemicals in women.

Irritant-induced asthma was first described in relation to a single exposure to high concentrations of irritants. There is increasing recognition that repeated workplace exposures to moderate levels of irritants also has an adverse effect in asthma, although whether such chronic exposure can cause new-onset asthma remains unclear [4]. Although the biological processes by which irritant cleaning products induce asthma onset or exacerbations are unknown, it has been proposed that irritants may induce injury of the bronchial epithelium, triggering release of inflammatory mediators and/or increasing epithelium permeability $[1,4]$. Our results are consistent with the hypothesis that oxidative stress is one of the mechanisms through which respiratory irritants may cause epithelial damage.

In conclusion, the results suggest that occupational exposures to asthmogenic chemicals and irritants, in particular cleaning and disinfecting products, generate oxidative stress. Future research should investigate oxidative stress as one of the potential mechanisms of chemical- or irritant-induced occupational asthma.

@ERSpublications

Associations between occupational exposures to asthmogenic chemicals and irritants and oxidative stress were found http://ow.ly/K6RSt

Orianne Dumas ${ }^{1,2,3,4}$, Régis Matran ${ }^{5}$, Farid Zerimech ${ }^{6}$, Brigitte Decoster ${ }^{5}$, Helene Huyvaert ${ }^{5,6}$, Ismail Ahmed ${ }^{7,8}$, Nicole Le Moual ${ }^{1,2}$ and Rachel Nadif ${ }^{1,2}$

${ }^{1}$ INSERM U1168, VIMA: Aging and chronic diseases, Epidemiological and public health approaches, Villejuif, France. ${ }^{2}$ Univ Versailles St-Quentin-en-Yvelines, UMR-S 1168, Montigny le Bretonneux, France. ${ }^{3}$ Channing Division of Network Medicine, Dept of Medicine, Brigham and Women's Hospital, Boston, MA, USA. ${ }^{4}$ Dept of Emergency Medicine, Massachusetts General Hospital, Boston, MA, USA. ${ }^{5}$ Univ Lille Nord de France, Lille, France. ${ }^{6}$ Laboratoire de Biochimie, Centre de Biologie Pathologie, CHRU de Lille, Lille, France. ${ }^{7}$ INSERM UMR 1181 "Biostatistics, Biomathematics, Pharmacoepidemiology and Infectious Diseases» (B2PHI), Villejuif, France. ${ }^{8}$ Univ Versailles StQuentin-en-Yvelines, UMR 1181, B2PHI, Montigny le Bretonneux, France.

Correspondence: Rachel Nadif, INSERM U1168, VIMA: Aging and chronic diseases, Epidemiological and public health approaches, F-94807, Villejuif, France. E-mail: rachel.nadif@inserm.fr

Received: Sept 262014 | Accepted after revision: Feb 04 2015 | First published online: April 022015 
Support statement: This work was funded by the French Agency of Health Safety, Environment and Work (AFSSET, EST- 09-15), Merck Sharp \& Dohme (MSD), the hospital program of clinical research (PHRC)-Paris, the National Research Agency - Health Environment, Health-Work Program (ANR 05-SEST-020-02/05-9-97, ANR CES-2009; Region Nord Pas-de-Calais), the Fondation pour la Recherche Médicale (SPE20130326585), and the Fond de dotation Recherche en Santé Respiratoire 2013. Funding information for this article has been deposited with FundRef

Conflict of interest: None declared.

Acknowledgements: The authors thank all those who participated in the study and in the various aspects of the examinations and all those who supervised the study centres. The authors are grateful to the three CIC-Inserm units at Necker, Grenoble and Marseille (France), which supported the study and where subjects were examined. They are also grateful to the three biobanks in Lille (CIC Inserm), Evry (Centre National de Genotypage) and Annemasse (Etablissement Français du Sang; France) where biological samples are stored. The authors thank Sylwester Karpiel (INSERM U1018, Centre for research in Epidemiology and Population Health (CESP), Respiratory and Environmental Epidemiology Team, Villejuif, France) for his contribution to this work. They are indebted to all the individuals who participated, without whom the study would not have been possible. The EGEA cooperative group are as follows. Coordination: V. Siroux (epidemiology, PI since 2013); F. Demenais (genetics); I. Pin (clinical aspects); R. Nadif (biology); F. Kauffmann (PI $1992-$ 2012). Respiratory epidemiology: Inserm U 700, Paris: M. Korobaeff (Egea1) and F. Neukirch (Egea1); Inserm U 707, Paris: I. Annesi-Maesano (Egea1-2); Inserm CESP/U 1018, Villejuif: F. Kauffmann, N. Le Moual, R. Nadif, MP. Oryszczyn (Egeal-2) and R. Varraso; Inserm U 823, Grenoble: V. Siroux. Genetics: Inserm U 393, Paris: J. Feingold; Inserm U 946, Paris: E. Bouzigon, F. Demenais and M.H. Dizier; CNG, Evry: I. Gut (now CNAG, Barcelona, Spain) and M. Lathrop (now McGill University, Montreal, Canada). Clinical centres: Grenoble: I. Pin and C. Pison; Lyon: D. Ecochard (Egea1), F. Gormand and Y. Pacheco; Marseille: D. Charpin (Egea1) and D. Vervloet (Egea1-2); Montpellier: J. Bousquet; Paris Cochin: A. Lockhart (Egea1) and R. Matran (now in Lille); Paris Necker: E. Paty (Egea1-2) and P. Scheinmann (Egea1-2); Paris-Trousseau: A. Grimfeld (Egea1-2) and J. Just. Data and quality management: Inserm ex-U155 (Egea1): J. Hochez Inserm CESP/U 1018, Villejuif: N. Le Moual; Inserm ex-U780: C. Ravault (Egea1-2); Inserm ex- U794: N. Chateigner (Egeal-2); Grenoble: J. Quentin-Ferran (Egea1-2).

\section{References}

$1 \quad$ Tarlo SM, Lemiere C. Occupational asthma. N Engl J Med 2014; 370: 640-649.

2 Siracusa A, De Blay F, Folletti I, et al. Asthma and exposure to cleaning products - a European Academy of Allergy and Clinical Immunology task force consensus statement. Allergy 2013; 68: 1532-1545.

3 Maestrelli P, Boschetto P, Fabbri LM, et al. Mechanisms of occupational asthma. J Allergy Clin Immunol 2009; 123: 531-542.

4 Tarlo SM. Irritant-induced asthma in the workplace. Curr Allergy Asthma Rep 2014; 14: 406.

5 Wu T, Willett WC, Rifai N, et al. Plasma fluorescent oxidation products as potential markers of oxidative stress for epidemiologic studies. Am J Epidemiol 2007; 166: 552-560.

6 Siroux V, Boudier A, Bousquet J, et al. Phenotypic determinants of uncontrolled asthma. J Allergy Clin Immunol 2009; 124: 681-687.

$7 \quad$ Kennedy SM, Le Moual N, Choudat D, et al. Development of an asthma specific job exposure matrix and its application in the epidemiological study of genetics and environment in asthma (EGEA). Occup Env Med 2000; 57: 635-641.

8 Donnay C, Denis MA, Magis R, et al. Under-estimation of self-reported occupational exposure by questionnaire in hospital workers. Occup Env Med 2011; 68: 611-617.

9 Yang S, Feskanich D, Willett WC, et al. Association between global biomarkers of oxidative stress and hip fracture in postmenopausal women: a prospective study. J Bone Miner Res 2014; 29: 2577-2583.

10 Jensen MK, Wang Y, Rimm EB, et al. Fluorescent oxidation products and risk of coronary heart disease: a prospective study in women. J Am Heart Assoc 2013; 2: e000195.

11 Hart JE, Wu T, Laden F, et al. Plasma fluorescent oxidation products and short-term occupational particulate exposures. Am J Ind Med 2012; 55: 953-960.

12 Vizcaya D, Mirabelli MC, Orriols R, et al. Functional and biological characteristics of asthma in cleaning workers. Respir Med 2013; 107: 673-683.

13 Dumas O, Donnay C, Heederik D, et al. Occupational exposure to cleaning products and asthma in hospital workers. Occup Env Med 2012; 69: 883-889.

14 Le Moual N, Varraso R, Siroux V, et al. Domestic use of cleaning sprays and asthma activity in females. Eur Respir J 2012; 40: 1381-1389.

15 Le Moual N, Rava M, Siroux V, et al. Use of household cleaning products, exhaled nitric oxide and lung function in females. Eur Respir J 2014; 44: 816-818.

16 Malorni W, Campesi I, Straface E, et al. Redox features of the cell: a gender perspective. Antioxid Redox Signal 2007; 9: 1779-801. 